\title{
Nucleotide sequence of the rhaR-sodA interval specifying rhaT in Escherichia coli
}

\author{
C. Garcia-Martin, L. Baldomà, J. Badía and J. Aguilar* \\ Department of Biochemistry, School of Pharmacy, University of Barcelona, Diagonal 643, 08028 Barcelona, Spain
}

(Received 18 October 1991; revised 18 February 1992; accepted 24 February 1992)

\begin{abstract}
The precise location of the rha $T$ gene, encoding rhamnose permease, has been established between sodA and rhaC at 3605-3607 kb of Kohara's physical map, which corresponds to 88.4 min on the Escherichia coli chromosomal map. The dependence of the activity of the rhaT product on the function of $r h a C$, the rhamnose operon regulatory gene, was established by measuring rhamnose transport in wild-type and rhaC-deficient strains. The sequence of the sodA-rhaC interval displayed a single ORF corresponding to rhaT, which is transcribed counterclockwise on the $E$. coli chromosome. The ORF was shown to be preceded by a ribosome binding consensus sequence and a catabolite repression protein consensus sequence. The derived amino acid sequence displayed very low homology with any other permease and was clearly dissimilar to the homologous group formed by the xylose, arabinose, galactose and several glucose transporters. Analysis of the rha $T$ primary sequence identified potential membranespanning regions, possibly defining a protein structure model different from the one corresponding to the abovementioned homologous group.
\end{abstract}

\section{Introduction}

Rhamnose utilization requires the function of a specific rhamnose transport system (Baldomà et al., 1990) which, although it has never been demonstrated experimentally, has been assumed to be induced by the presence of the methylpentose. Thus, the structural rhaT gene, encoding rhamnose permease, would be under the control of the rhamnose regulatory gene $r h a C$, formed by two overlapping genes, rhaR and rhaS (Tobin \& Schleif, 1989). These regulatory genes control the three other structural genes forming the rhamnose operon: rhaA, encoding rhamnose isomerase; rhaB, encoding rhamnulose kinase and $r h a D$, encoding rhamnulose-1-phosphate aldolase (Power, 1967).

The rhaT gene has been mapped in the rha locus at $88.4 \mathrm{~min}$ on the Escherichia coli chromosome, separated from $r h a A, r h a B$ and $r h a D$ by their regulatory gene $r h a C$ (Power, 1967; Badía et al., 1989; Baldomà et al., 1990). The precise location of the three structural genes has been determined by complementation analysis of mutants with different alterations in rhamnose metabolism

* Author for correspondence. Tel. 333079 63; fax 34908274 .

The nucleotide sequence data reported in this paper have been submitted to EMBL and have been assigned the accession number X60699. and by enzymic assays of strains transformed with recombinant plasmids containing different parts of the cloned rhamnose operon (Badía et al., 1989). In the case of rhaT, the gene has been located in a $4.6 \mathrm{~kb}$ BamHIEcoRI fragment encompassing rhaC by analysis of cotransduction with $g l p K$ and other $r h a$ markers, and also by complementation of rhamnose transport mutants characterized by their ability to grow on rhamnose at concentrations of $50 \mathrm{mM}$, but not at $10 \mathrm{mM}$ (Baldomà et $a l ., 1990)$. The resulting gene order (counter-clockwise) is thus glpK ...rhaT-rhaR-rhaS-rhaB-rhaA-rhaD. The $r h a T$ gene has been cloned and its product indentified by expression in a T7 RNA polymerase/promoter system yielding a $23 \mathrm{kDa}$ protein that has been shown to be located in the membrane (Baldomá et al., 1990). In this report we present the precise location of rhaT, which is shown to be under the control of rhaC, and we specify and analyse the nucleotide sequence of the rhaR-sodA interval which contains only the ORF encoding rhaT.

\section{Methods}

Bacterial strains and plasmids. The $E$. coli strains and plasmids used are listed in Table 1. The strain XL1Blue was used as a host for the Bluescript recombinant plasmids. Mutations in $r h a C$ and $r h a A$ were obtained by insertion of $\mathrm{Tn} 5$ by infecting strain ECL $1\left(10^{9}\right.$ cells $\left.\mathrm{ml}^{-1}\right)$ with phage $\lambda 467$ (b221 cIts857 rex:: Tn5 Oam29 Pam80) at a m.o.i. of 
Table 1. E. coli strains and plasmids used

\begin{tabular}{|c|c|c|}
\hline $\begin{array}{l}\text { Strain or } \\
\text { plasmid }\end{array}$ & Relevant genotype & $\begin{array}{l}\text { Source or } \\
\text { reference }\end{array}$ \\
\hline \multicolumn{3}{|l|}{$\begin{array}{l}E . \text { coli } \\
\text { strains }\end{array}$} \\
\hline ECL1 & $\mathrm{HfrC}$ phoA8 relAl tonA22 $\mathrm{T}^{r}(\lambda)$ & E. C. C. Lin* \\
\hline JA117 & ECL1 rhaC::Tn5 & This study \\
\hline JA118 & ECL1 rhaA::Tn5 & This study \\
\hline JA107 & ECL1 rhaT::Tns & $\begin{array}{l}\text { Baldomà et al. } \\
\text { (1990) }\end{array}$ \\
\hline JA109 & $\begin{array}{l}\text { MC4100 rbs7 pcnB80 rhaT::Tn5 } \\
\text { recA ::cat }\end{array}$ & $\begin{array}{l}\text { Baldomà et al. } \\
\text { (1990) }\end{array}$ \\
\hline XL1-Blue & $\begin{array}{l}\text { recAl lac }- \text { endAl gyrA96 thi hsdR17 } \\
\text { supE } 44 \text { relA1 }\left\{\mathrm{F}^{\prime} \text { proAB lacZ M15 }\right. \\
\text { Tn10\} }\end{array}$ & Stratagene \\
\hline \multicolumn{3}{|l|}{ Plasmids } \\
\hline $\begin{array}{l}\text { Bluescript } \\
\text { pLB2 }\end{array}$ & $\begin{array}{l}\mathrm{Ap}^{\mathrm{r}} \text { lacZ } \\
\text { rhaTC (4.6 kb EcoRI-BamHI } \\
\text { fragment) in pBR322, } \mathrm{Ap}^{\mathrm{r}}\end{array}$ & $\begin{array}{l}\text { Stratagene } \\
\text { Baldomà et al. } \\
\text { (1990) }\end{array}$ \\
\hline pCG1 & $\begin{array}{l}\operatorname{rhaT}(1.6 \mathrm{~kb} \text { Pst I-SmaI } \\
\text { fragment) in Bluescript, Ap }\end{array}$ & This study \\
\hline
\end{tabular}

* E.C.C. Lin, Harvard Medical School, Boston, MA, USA.

0.5 (Bruijn \& Lupsky, 1984) and selected by their inability to grow on $10 \mathrm{~mm}$-L-rhamnose. The rhaC mutant (strain JA117) was identified by the absence of all the enzyme activities of L-rhamnose metabolism (for assays, see below) when cells were grown on $0.5 \%$ casein acid hydrolysate in the presence of $10 \mathrm{~mm}$-rhamnose. The rhaA mutant (strain JA118) was identified by the absence of rhamnose isomerase activity in its extract, while the rhamnulose kinase and rhamnulose-1phosphate aldolase levels were the same as those found in wild-type strain ECL1 when grown under the same conditions.

Media and growth conditions. For enzyme and transport assays, cells were grown aerobically in minimal medium (Boronat \& Aguilar, 1979) containing $0.5 \%$ casein acid hydrolysate and $10 \mathrm{mM}-\mathrm{L}$-rhamnose as inducer.

Selection of Bluescript recombinant plasmids was performed on LBagar plates containing X-Gal $\left(30 \mu \mathrm{g} \mathrm{ml}^{-1}\right)$, IPTG $\left(10 \mu \mathrm{g} \mathrm{ml}^{-1}\right)$ and ampicillin $\left(100 \mu \mathrm{g} \mathrm{m}^{-1}\right)$.

DNA manipulation. Plasmid DNA was isolated from $E$. coli by the boiling method described by Sambrook et al. (1989). For large-scale preparation, DNA in a crude sample was purified by chromatography on a Qiagen column (Diagen). DNA manipulations such as restriction endonuclease cleavage, ligation, transformation, Southern transfers and hybridization were performed as described by Sambrook et al. (1989). DNA fragments were purified using a kit (Geneclean, Biol01).

Nucleotide sequencing. For DNA sequencing, the DNA fragments were subcloned into appropriate Bluescript plasmids (Stratagene) and exonuclease III was used to generate two sets of overlapping deletions of opposite polarity (Henikoff, 1984). The DNA sequence was determined by using the dideoxy-chain termination procedure of Sanger et al. (1977) and a sequencing kit (T7 Sequencing Mixes; Pharmacia LKB). Double-stranded plasmid DNA was prepared for use as a template. In order to resolve the numerous sequencing gel compressions, 7-deaza-dGTP and 7-deaza-dITP were used instead of dGTP.

Preparation of cell extracts and enzyme assays. Cell extracts were prepared as described by Boronat \& Aguilar (1979). L-Rhamnose isomerase activity was determined from the initial rate of ketose formation measured by the cysteine-carbazole method (Takagi \&
Sawada, 1964). L-Rhamnulose kinase and L-rhamnulose-1-phosphate aldolase activities were determined as described by Chiu \& Feingold (1964, 1969).

Transport assays. L-Rhamnose permease activity was determined by the rate of $\mathrm{L}^{-}\left[{ }^{14} \mathrm{C}\right] \mathrm{rhamnose}\left[210 \mathrm{mCi} \mathrm{mmol}^{-1}\left(7.77 \mathrm{GBq} \mathrm{mmol}^{-1}\right)\right.$; CEA, GifSur-Yvette, France] uptake by whole cells. Cells were harvested and the assay was performed as described for fucose transport by Hacking \& Lin (1976) using a rhamnose concentration of $0.2 \mathrm{mM}\left[0.8 \mathrm{mCi} \mathrm{mmol}^{-1}\left(29.6 \mathrm{MBq} \mathrm{mmol}^{-1}\right)\right]$.

\section{Results and Discussion}

\section{Induction of rhamnose permease}

The dependence of the structural genes on $r h a C$ function has been experimentally demonstrated for rhaA, rhaB and $r h a D$ but not for $r h a T$, a gene generally assumed to belong to the rhamnose operon. The control of rhaT expression by rhaC was shown by measuring rhamnose transport in cells, derived from wild-type strain ECL1, which are deficient for rhamnose metabolism. As shown in Fig. 1, strain JA118, a rhamnose isomerase mutant, incorporated rhamnose to saturation in 2-3 min, whilst the wild-type strain, ECL1, incorporated the labelled sugar at the same rate and displayed no saturation. Strain JA117 with a mutation in rhaC, and hence unable to induce the rhamnose metabolic enzymes, was completely deficient in rhamnose transport. As predicted, an absence of rhamnose transport was also observed in the rhaT mutant strain JA107 (Fig. 1). Thus it may be concluded that rhaC is required for rhaT function. The rhaT gene, although inevitably transcribed separately from the other three structural genes as a consequence of the gene order in the rhamnose operon (Baldomà et al., 1990), must be coordinately expressed with these genes under the control of this regulatory gene.

\section{Identification of the rhaT gene in plasmid pLB2}

Additional evidence for the presence of the rhaT gene in the cloning plasmid pLB2 (Baldomà et al., 1990) came from the location of the $\mathrm{Tn} 5$ insertion that blocked rhamnose transport in strain JA107 used in isolation of the clone. For this mapping, chromosomal DNA of strains JA107 and ECLl was digested with BamHI and, after Southern transfer, genomic fragments were analysed using the $2 \cdot 2 \mathrm{~kb} \mathrm{BglI}$ fragment as a probe (Fig. 2). From the number and size of the labelled fragments, the Tn5 insertion was located in the $1.6 \mathrm{~kb}$ Pst I-SmaI fragment at $0.6 \mathrm{~kb}$ from the Pst I restriction site (not shown), thus localizing rhaT in this fragment. Furthermore, sequence data presented in Fig. 4 showed a single ORF between the identified sequences of rhaR and sodA, leaving no more space for any other ORF that could lead to erroneous identification of rhaT. 


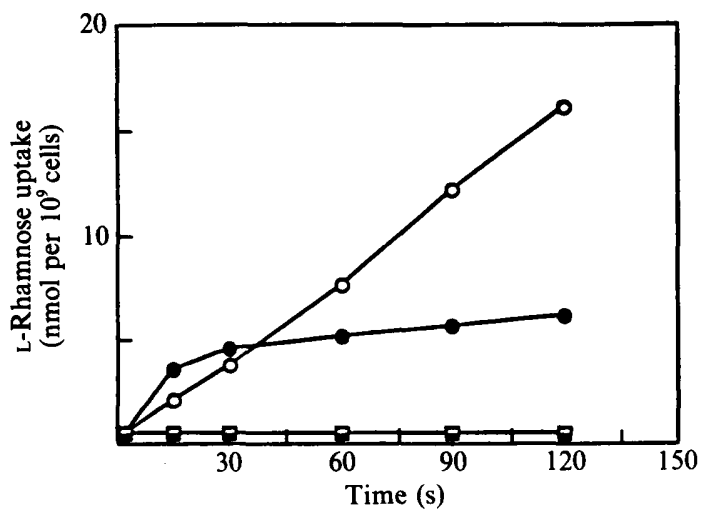

Fig. 1. Dependence of rhamnose transport on the function of $r h a C$ and rhaT. Time course of $\mathrm{L}-\left[{ }^{14} \mathrm{C}\right]$ rhamnose uptake by whole cells is plotted for wild-type ECL1 (O), rhamnose-isomerase-deficient JA118 (O), rhamnose-permease-deficient JA107 ( $\square$ ) and rhamnose-regulatorminus JA117 ( $\mathbf{\square})$.

(a)

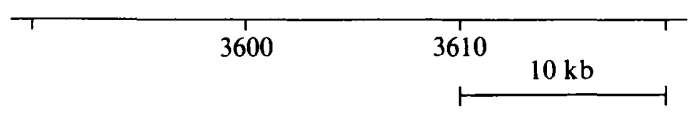

(b)
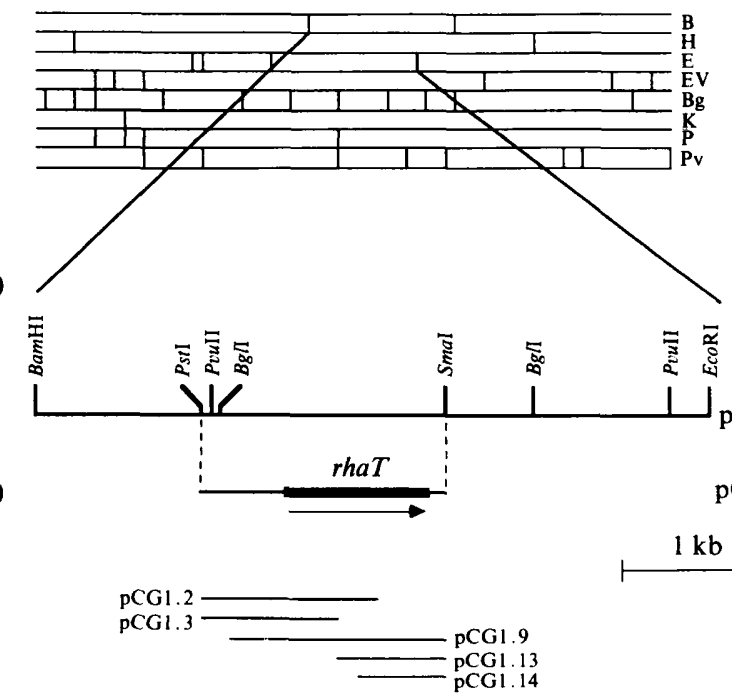

Fig. 2. (a) Fragment of the restriction map of Kohara et al. (1987) encompassing the $r h a T$ gene. The restriction sites for several enzymes are indicated in the horizontal open bars, which are labelled as follows: B, Bam HI; H, HindIII; E, EcoRI; EV, EcoRV; Bg, BglI; K, Kpn; P, Pst I; Pv, PvuII. (b) Restriction map of the insert of plasmid PLB2 and its correspondence to the map of Kohara et al. (1987). (c) Deletion analysis of the $1.6 \mathrm{~kb}$ Pst I-SmaI insert of plasmid pCG1. The thick line represents the DNA fragment of pCG1. Thinner lines below pCGl represent the fragments of several subclones constructed by deletion of pCG1, which were used for the complementation analysis of rhaT mutations (Table 2). The solid bar represents the rhaT coding region. The arrow indicates the direction of transcription.
Table 2. Complementation of the rhaT mutation of strain $J A 109$ by different plasmids obtained after deletion of pCGI

Cells of strain JA109 transformed with different plasmids were grown on casein acid hydrolysate in the presence of $10 \mathrm{~mm}$ L-rhamnose as inducer. L-Rhamnose uptake was determined as described in Methods.

\begin{tabular}{|c|c|}
\hline Plasmid & 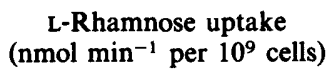 \\
\hline $\mathrm{pCG} 1$ & $7 \cdot 2$ \\
\hline pCG 1.2 & 0.0 \\
\hline pCG 1.3 & 0.0 \\
\hline pCG1.9 & 7.5 \\
\hline pCG 1.13 & 0.0 \\
\hline pCG1.14 & 0.0 \\
\hline
\end{tabular}

\begin{tabular}{llll}
0 & 0.5 & 1 & $1.5 \mathrm{~kb}$ \\
\hline
\end{tabular}
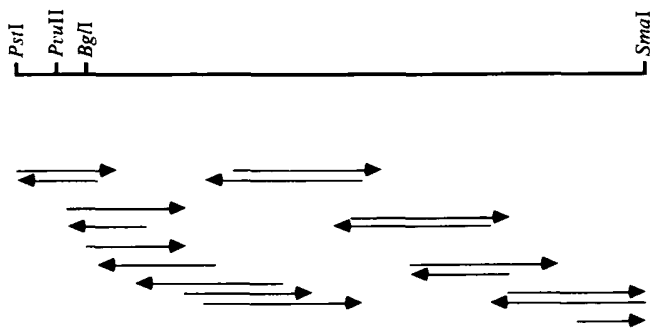

Fig. 3. Sequencing strategy for the $1.6 \mathrm{~kb}$ Pst I-SmaI fragment in plasmid pCG1. The arrows indicate the start-point, direction and extent of sequence determined from each subclone. The open rectangle at the bottom of the figure shows the extent of the rhaT gene.

\section{Determination of the rhaT coding region}

To locate rhaT with precision in the $4.6 \mathrm{~kb}$ BamHIEcoRI fragment of plasmid pLB2 encompassing rhaC (Fig. 2), this construction was further digested with several restriction enzymes. By comparing the restriction map of the rhaT region with the corresponding region of the physical map of Kohara et al. (1987), we found that the rhaT gene is located between $3605-3607 \mathrm{~kb}$ on this physical map. However, due to the inversion of this region present in the strain used by Kohara et al. (1987) this location does not correlate with the genetic mas (Bachmann, 1990) in which rhaT is mapped at around $88.4 \mathrm{~min}$ on the chromosome. Sequence analysis of the rhaT region has shown that the start codon of the ORF of the rhaT gene is proximal to the BamHI site and distal to the EcoRI site on plasmid pLB2 (Fig. 2). Accordingly, the rhaT gene is transcribed counter-clockwise on the $E$. coli chromosome. 
10

20

30

40

50

60

CTGCAGGGTGGTGCCTTTTTTCAGACCTTTCCAGAACAGGCTGTGGTTAGCGTGACCGCC

70

80

90

100

110

120

AGCGTTGTTGCGCAGTACGGTTTTCTTGTCTGCTGGCAGCTGGTCCAGTTTGGTGATCAG

$130 \quad 140 \quad 150 \quad 160 \quad 170 \quad 180$

CTCTTCAACCGGCAGGTTGGCAAATTCTGGCAGGCTTTCCAGCGCCGCGTTGGCGTTGTT

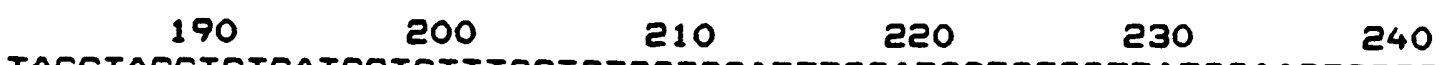

TACGTAGGTCTGATGGTGTTTGGTGTGGTGGATTTCCATGGTCTGCTTATCGAAGTGCGG

$250 \quad 260 \quad 270 \quad 2802 \% 300$

TTCCAGGGCATCGTAAGCATACGGCAGGGATGGCAGGGTATAGCTCATATTCATCTCCAG

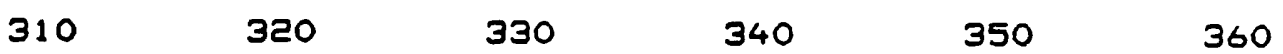

TATTGTCGGGCGGCCGATTGTTAATGCCGCGTAAGCAGTTGGTTCATTATAGTTAATTAA

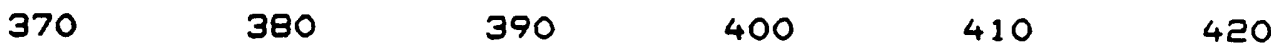
ATGATATTGAAAATGATTATCAATGCCGTACTTTTCGTAAGGGTATGGTTTTGCAGGAAA

$430 \quad 440 \quad 450 \quad 460 \quad 470 \quad 480$ ATGCCCGAGATGTGAAGCAAATCACCCACTTAATGCCGTGATTGCCAGTAAATCGACAAC

$490 \quad 500 \quad 510 \quad 520 \quad 530 \quad 540$ GGCGGCAACAGGCGAAAGGTTAATCGACAGCACGATTTTTACACTCATCTCGTCGGAGAT

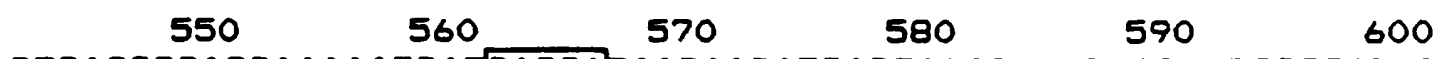
GTGACGCGACGAAAAATGA GAGGATAAGAAGATGAGTAACGCGATTACGATGGGGATAT $\begin{array}{lllllllll}M & S & N & A & I & T & M & G & I\end{array}$

$6106200630 \quad 620650 \quad 60$

TTTGGCATTTGATCGGCGCGGCCAGTGCAGCCTGTTTTTACGCTCCGTTCAAAAAAGTAA $\begin{array}{llllllllllllllllllll} & W & H & L & I & G & A & A & S & A & A & C & F & Y & A & P & F & K & K & V\end{array}$

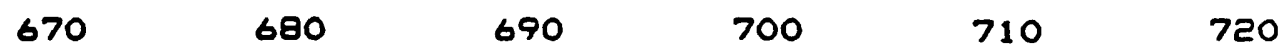
AAAAATGGTCATGGGAAACCATGTGGTCAGTCGGTGGGATTGTTTCGTGGATTATTCTGC

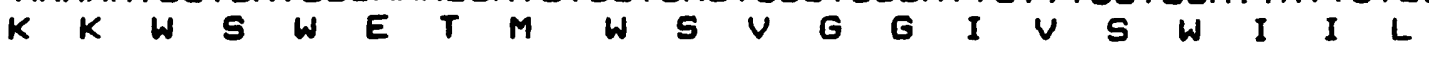

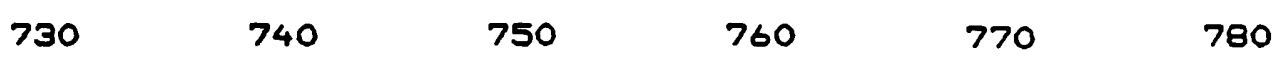
CGTGGGCCATCAGCGCCCTGTTACTACCGAATTTCTGGGCGTATTACAGCTCGTTTAGTC $\begin{array}{llllllllllllllllllll}P & W & A & I & S & A & L & L & L & P & N & F & W & A & Y & Y & S & S & F & S\end{array}$

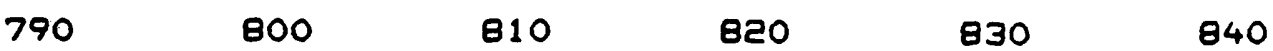
TCTCTACGCGACTGCCTGTTTTTCTGTTCGGCGCTATGTGGGGGATCGGTAATATCAACT $\begin{array}{llllllllllllllllllllllllll} & S & T & R & L & P & V & F & L & F & G & A & M & W & G & I & G & N & I & N\end{array}$ 


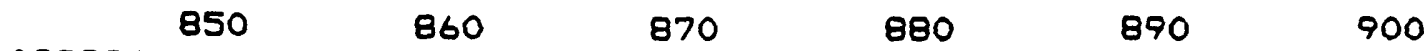

ACGGCCTGACCATGCGTTATCTCGGCATGTCGATGGGAATTGGCATCGCCATTGGCATTA $\begin{array}{llllllllllllllllllll}Y & G & L & T & M & R & Y & L & G & M & S & M & G & I & G & I & A & I & G & I\end{array}$ $910 \quad 920 \quad 930 \quad 940 \quad 950 \quad 960$ CGTTGATTGTCGGTACGCTGATGACGCCAATTATCAACGGCAATTTCGATGTGTTGATTA

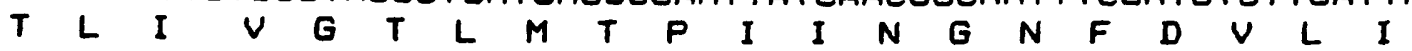
$970 \quad 980 \quad 990 \quad 1000 \quad 1010 \quad 1020$ GCACCGAAGGCGGACGCATGACGTTGCTCGGCGTTCTGGTGGCGCTGATTGGCGTAGGGA

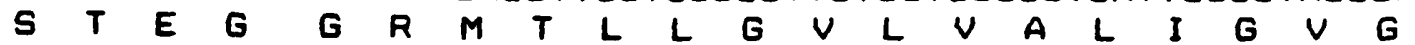
$\begin{array}{llllll}1030 & 1040 & 1050 & 1060 & 1070 & 1080\end{array}$ TTGTAACTCGCGCCGGGCAGTTGAAAGAGCGCAAGATGGGCATTAAAGCCGAAGAGTTCA

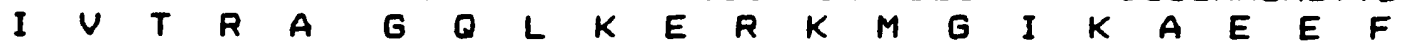
$1090 \quad 1100 \quad 1110 \quad 1120 \quad 1130 \quad 1140$

ATCTGAAAAAAGGGCTGGTGCTGGCGGTGATGTGCGGCATTTTCTCTGCCGGGATGTCCT

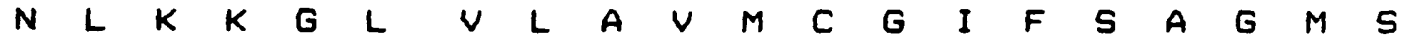
$1150 \quad 1160 \quad 1170 \quad 1180 \quad 1190 \quad 1200$ TTGCGATGAACGCCGCAAAACCGATGCATGAAGCCGCTGCCGCACTTGGCGTCGATCCAC

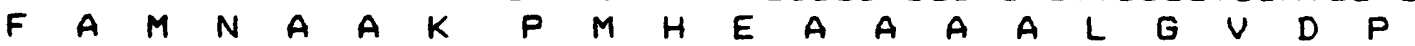
$121011220 \quad 1230 \quad 1240 \quad 1250 \quad 1260$ TGTATGTCGCTCTGCCAAGCTATGTTGTCATCATGGGCGGCGGCGCGATCATTAACCTCG

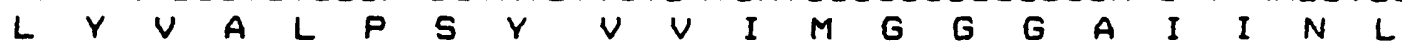

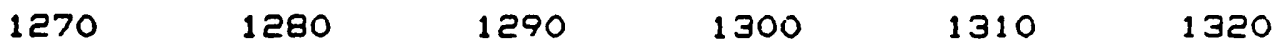
GTTTCTGTTTTATTCGTCTGGCAAAAGTGAAGGATTTGTCGCTAAAAGCCGACTTCTCGC $\begin{array}{llllllllllllllllllll}G & F & C & F & I & R & L & A & K & V & K & D & L & S & L & K & A & D & F & S\end{array}$ $\begin{array}{llllll}1330 & 1340 & 1350 & 1360 & 1370 & 1380\end{array}$ TGGCAAAATCGCTGATCATTCACAATGTGTTACTCTCGACACTGGGCGGGTTGATGTGGT $\begin{array}{lllllllllllllllllllll}L & A & K & S & L & I & I & H & N & V & L & L & S & T & L & G & G & L & M & W\end{array}$ $1390 \quad 1400 \quad 1410 \quad 1420 \quad 1430 \quad 1440$ ATCTGCAATTCTTTTTCTATGCCTGGGGCCACGCCCGCATTCCGGCGCAGTATGACTACA $\begin{array}{lllllllllllllllllllll} & L & D & F & F & F & Y & A & W & G & H & A & R & I & P & A & Q & Y & D & Y\end{array}$ $\begin{array}{llllll}1450 & 1460 & 1470 & 1480 & 1490 & 1500\end{array}$ TCAGTTGGATGCTGCATATGAGTTTCTATGTATTGTGCGGCGGTATCGTCGGGCTGGTGC

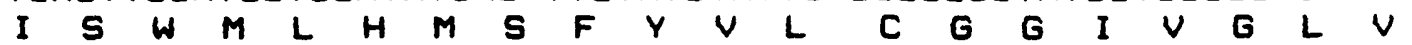
$\begin{array}{llllll}1510 & 1520 & 1530 & 1540 & 1550 & 1560\end{array}$ TGAAAGAGTGGAACAATGCAGGACGCCGTCCGGTAACGTGTTGAGCCTCGGTTGTGTGGT $L \quad K \quad E \quad W \quad N \quad N \quad A \quad G \quad R \quad R \quad P \quad V \quad T \quad C$. $1570 \quad 1580 \quad 1590 \quad 1600 \mid \bullet \frac{t^{\text {rhaR }}}{1610} 1620$ GATTATTGTCGCCGCTAACATCGTCGGCATCGGCATGGCGAATTAATCTTTCTGCGAATT

\section{$163011640 \quad 1650 \quad 1660$ \\ GAGATGACGCCACTGGCTGGGCGTCATCCCGGTTTCCCGGG}

Fig. 4. Nucleotide sequence of the rhaR-sodA interval specifying rhaT. The coding region of rhaT has been translated and is indicated using the single letter amino acid code. The putative Shine-Dalgarno sequence is boxed. The inverted repeat constituting a good catabolite repression protein consensus binding site is underlined twice. The position and direction of genes rha $R$ and $\operatorname{sod} A$ encoded in the complementary strand are also indicated. Stop codons are indicated by a dot. 
Restriction sites for PstI and SmaI in plasmid pLB2 specified a $1.6 \mathrm{~kb}$ fragment that was subcloned into a Bluescript vector yielding plasmid pCG1 (Fig. 2), which also complemented rhaT. The assay required the pcnB mutation, present in strain JA109, to avoid toxicity effects (Baldomà et al., 1990).

Since the rhaT gene product has been described by Baldomà et al. (1990) as a protein with an estimated molecular mass of $23 \mathrm{kDa}$, the ORF encoding rhaT would probably not exceed the limits of the Pst I-SmaI fragment. This would also be true if, as indicated by Maiden et al. (1988) for other hydrophobic proteins, the $23 \mathrm{kDa}$ estimated by electrophoresis for rhamnose permease corresponded to more than $30 \mathrm{kDa}$ or a protein of over 300 amino acids. These data imply that the PstISmaI fragment includes the entire $r h a T$ and that no part of the gene was beyond its limits.

Several nuclease deletions were obtained from plasmid pCG1. The deletions were checked for their capacity to complement rhaT mutant strain JA109 by determining the rhamnose uptake of this strain when transformed with the plasmids containing the different deletions (Table 2). Since only pCG1 and pCG1.9 restored Lrhamnose uptake, the limits of rhaT were thus determined more precisely.

\section{Nucleotide sequence of the rhaT coding region}

Plasmid pCG1 was used for sequencing the genomic insert and a diagram of the sequencing procedure is shown in Fig. 3. The sequence of the 1661 bp Pst I-SmaI fragment, derived from both DNA strands and fully overlapped, displayed an ORF from positions 573 to 1544 encoding a single 323 amino acid polypeptide of $35320 \mathrm{Da}$ (Fig. 4) which was identified as rhamnose permease on the basis of the complementation data indicated above. In the $3^{\prime}$-flanking region of the rhaT ORF, the complementary sequence at the $3^{\prime}$ end of rhaR (Tobin \& Schleif, 1989) was identified. In addition, $5^{\prime}$ to $r h a T$, another ORF started for a divergently transcribed gene which corresponded to $\operatorname{sodA}$ as described by Takeda \& Avila (1986). Normal codon usage was found for the rhaT ORF according to the method of Ikemura (1981).

\section{Features of the rhaT primary sequence}

A good ribosome binding site is found at position 561 565,8 nucleotides upstream of the ATG initiation codon of rhaT (Fig. 4). A TGTGA motif appears at position 431-435 with a highly conserved inverted repeat 6 nucleotides downstream, constituting a good catabolite repression protein consensus binding site (Fig. 4). However, no clear -10 or -35 consensus sequences for

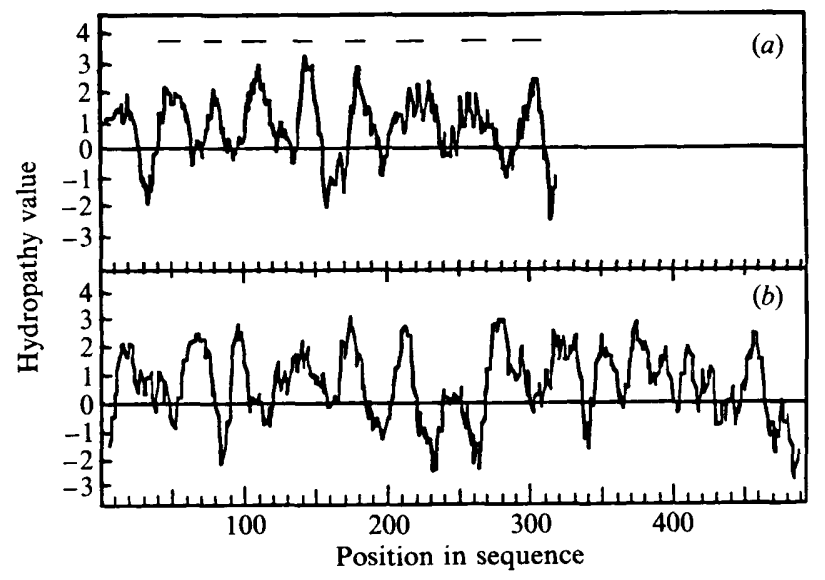

Fig. 5. Hydropathic profiles of (a) L-rhamnose permease and (b) xylose- $\mathrm{H}^{+}$transporter. Hydropathy values (Kyte \& Doolittle, 1982) for a window of nine amino-acid residues were averaged and plotted according to the position of the middle residue along the length of each sequence. Bars denote predicted membrane-spanning $\beta$-strands for L-rhamnose permease.

RNA polymerase $\sigma^{70}$ binding are apparent, which is not unusual in a gene belonging to an operon under positive control (deCrombrugghe et al., 1984; Collado-Vides et al., 1991).

The rhaT ORF encodes a highly hydrophobic protein ( $47 \%$ hydrophobic residues), as would be expected for a cytoplasmic membrane protein. Comparison of the deduced amino acid sequence of rhaT revealed no significant similarity to sequences in the GenBank protein data bank or to any of the transporters of the homologous group integrated by xylose, arabinose, galactose or different glucose transporters (Henderson, 1990). The highest score ( $18 \%$ homology) was for a 156 amino acid overlap with the $x y l E$ product, xylose permease (Davis \& Henderson, 1987). This absence of homology seems to indicate that rhamnose permease belongs to a different family of transporters, perhaps integrated by as yet undescribed transport proteins other than those noted above. The rhamnose permease reported here does not have the two fundamental features indicated by Henderson \& Maiden (1990) as initial clues to classify a permease in a homologous group, namely: 12 membrane-spanning helices and a repeated motif RXGRR, proposed to form a $\beta$-turn linking adjacent helices. Furthermore, none of the amino acid residues, consensus motifs or central hydrophilic regions conserved in the xylose, arabinose, galactose and different glucose transporters group are apparent in the $E$. coli rhamnose permease. Other transport proteins with dissimilar primary sequences have been reported, such as lactose, melibiose and fucose permeases (Henderson, 1990). None of them, however, presented homology with the rhamnose permease. The molecular 
mass of the rhamnose permease of Salmonella typhimurium $(37390 \mathrm{Da})$ is similar to that of $E$. coli $(35320 \mathrm{Da})$ and lower than the molecular mass reported for other permeases (Henderson, 1990), but the $S$. typhimurium rhaT sequence has not been published and comparison is not possible.

In spite of the low homology between $E$. coli rhamnose and xylose permeases, the hydrophobicity profiles (Kyte \& Doolittle, 1987) of the deduced amino acid sequences of the two proteins, are similar, but with two important differences (Fig. 5). First, the highly hydrophilic stretch of 50 amino acids of xylose permease (position 220-270) seems to be absent in rhamnose permease. Second, the hydrophobic domains determined by the sequences from amino acid 340 to the $C$-terminal end of xylose permease are absent in rhamnose permease.

Based on this hydropathy plot and on structure predictions of proteins, according to the Garnier algorithm (Garnier et al., 1978), eight potential $\beta$-strand membrane-spanning regions of at least 10 amino acids were estimated and these are indicated in Fig. 5. This could lead to a closed $\beta$-barrel structure as described by Jähnig (1990), in a model for the folding of this transport protein, alternative to the twelve $\alpha$-helices of the homologous group of transporters described by Henderson \& Maiden (1990). Absence of homology to other transporters of which the structure has been established does not allow alignment and comparison to ascertain the features of the transmembrane regions.

The $\mathrm{N}$-terminal part of the rhaT-derived amino acid sequence showed some similar features to those of signal peptides. The sequence displayed (i) presence of charged residues close to the $\mathrm{N}$-terminal, (ii) a hydrophobic midsection with an Ile residue at position 9, usually conserved as a Leu or Ile at position 8 (Scripture \& Hogg, 1983) or position 9 (Bedouelle et al., 1980), and (iii) an Ala-X-Ala described as immediately preceding the cleavage site between the signal peptide and the mature protein (Scripture \& Hogg, 1983). Determination of the $\mathrm{N}$-terminal structure of the mature protein is required to confirm processing of this 19 amino acid putative signal peptide. It is worth noting that not all these features of the signal peptides are conserved in the homologous group of transporters analysed by Henderson, (1990).

This work was supported by Grant PB 88-0215 from the Dirección General de Investigación Científica y Técnica, Spain. We thank Robin Rycroft for editorial assistance.

\section{References}

BACHMANN, B. J. (1990). Linkage map of Escherichia coli K12, edition 8. Microbiological Reviews 54, 130-197.

Badí, J., Baldomì, L., Aguilar, J. \& Boronat, A. (1989). Identification of the rhaA, rhaB and rhaD gene products from Escherichia coli K-12. FEMS Microbiology Letters 65, 253-258.
Baldomì, L., Badía, J., Sweet, G. \& Aguilar, J. (1990). Cloning mapping and gene product identification of rhaT from Escherichia coli K12. FEMS Microbiology Letters 72, 103-108.

Bedouelle, H., Bassford, P. J. JR, Fowler, A. W., Zabin, I., BECKWITH, J. \& HofNUNG, M. (1980). Mutations which alter the function of the signal sequence of the maltose binding protein of Escherichia coli. Nature, London 285, 78-81.

Boronat, A. \& AgulLaR, J. (1979). Rhamnose-induced propanediol oxidoreductase in Escherichia coli: purification, properties, and comparison with the fucose-induced enzyme. Journal of Bacteriology 140, 320-326.

BruiJn, F. J. \& LUPSKI, J. R. (1984). The use of transposon Tn5 mutagenesis in the rapid generation of correlated physical and genetic maps of DNA segments cloned into multicopy plasmids. Gene 27, 131-149.

CHIU, T. H. \& FeINGOLD, D. S. (1964). The purification and properties of L-rhamnulokinase. Biochimica et Biophysica Acta 92, 484-497.

ChIU, T. H. \& FeINGOLD, D. S. (1969). L-Rhamnulose-1-phosphate aldolase from Escherichia coli. Crystallization and properties. Biochemistry 8, 98-102.

Collado-Vides, J., Magasanik, B. \& Gralla, J. D. (1991). Control site location and transcriptional regulation in Escherichia coli. Microbiological Reviews 55, 371-394.

Davis, E. O. \& Henderson, P. J. F. (1987). The cloning and DNA sequence of the gene $x y l E$ for xylose-proton symport in $E$. coli $\mathrm{K}-12$. Journal of Biological Chemistry 262, 13928-13932.

deCrombrugghe, B., Busby, S. \& Buc, H. (1984). Cyclic-AMP receptor protein: role in transcription activation. Science 224, 831838.

Garnier, J., Osguthorpe, D. J. \& Robson, B. (1978). Analysis of the accuracy and implications of simple methods for predicting the secondary structure of globular proteins. Journal of Molecular Biology $120,97-120$

HACKING, A. J. \& Lin, E. C. C. (1976). Disruption of a fucose pathway as a consequence of genetic adaptation to propanediol as a carbon source in Escherichia coli. Journal of Bacteriology 126, 11661172.

HENDERSON, P. J. F. (1990). Proton-linked sugar transport systems in bacteria. Journal of Bioenergetics and Biomembranes 22, 525-569.

Henderson, P. J. F. \& MAIDEN, M. C. J. (1990). Homologous sugar transport proteins in Escherichia coli and their relatives in both prokaryotes and eukaryotes. Philosophical Transactions of the Royal Society of London 326, 391-410.

HENIKOFF, S. (1984). Unidirectional digestion with exonuclease III creates targeted breakpoints for DNA sequencing. Gene 28, 351359.

IKEMURA, T. (1981). Correlation between the abundance of $E$. coli transfer RNA and the occurrence of the respective codons in its proteins genes: a proposal for a synonymous codon choice that is optimal for the E. coli translational system. Journal of Molecular Biology 151, 389-409.

JÄHNIG, F. (1990). Structure predictions of membrane proteins are not that bad. Trends in Biochemical Sciences 15, 93-95.

Kohara, Y., Axiyama, K. \& Isono, K. (1987). The physical map of the whole $E$. coli chromosome: application of a new strategy for rapid analysis and sorting of a large genomic library. Cell 50, 495-508.

KYTE, J. \& DoolitTLE, R. F. (1982). A simple method for displaying the hydropathic character of a protein. Journal of Molecular Biology 157, 105-132.

Maiden, M. C. J., Jones-Mortimer, M. C. \& Henderson, P. J. F. (1988). The cloning, DNA sequence and overexpression of the gene araE coding for arabinose-proton symport in Escherichia coli K-12. Journal of Biological Chemistry 263, 8003-8010.

POWER, J. (1967). The L-rhamnose genetic system in Escherichia coli K-12. Genetics 55, 557-568.

Sambrook, J., Maniatis, T. \& Fritsch, E. F. (1989). Molecular Cloning. A Laboratory Manual, 2nd edn. Cold Spring Harbor, NY: Cold Spring Harbor Laboratory.

SANGer, F., Nicklen, S. \& Coulson, A. R. (1977). DNA sequencing with chain-terminating inhibitors. Proceedings of the National Academy of Sciences of the United States of America 74, 54635467. 
SCRIPTURE, J. B. \& HoGG, R. W. (1983). The nucleotide sequences defining the signal peptides of the galactose-binding protein and the arabinose-binding protein. Journal of Biological Chemistry 258, 10853-10855.

TAKAGI, Y. \& SAWADA, H. (1964). The metabolism of L-rhamnose in Escherichia coli. I. L-Rhamnose isomerase. Biochimica et Biophysica Acta 92, 10-17.
TAKeDA, Y. \& AvilA, H. (1986). Structure and gene expression of the E. coli Mn-superoxide dismutase gene. Nucleic Acids Research 14, 4577-4589.

Tobin, J. F. \& SchleIF, R. F. (1987). Positive regulation of the Escherichia coli L-rhamnose operon is mediated by the products of tandemly repeated regulatory genes. Journal of Molecular Biology 196, 789-799. 